\title{
Coping, academic engagement and performance in university students
}

\author{
Carmen Vizoso ${ }^{1}$, Celestino Rodríguez ${ }^{2}$ and Olga Arias-Gundín ${ }^{11}$ \\ ${ }^{1}$ Department of Psychology, Sociology, and Philosophy, León University \\ ${ }^{2}$ Department of Psychology, Oviedo University
}

\begin{abstract}
The aim of this study is to evaluate the relationships between coping (i.e., adaptive or maladaptive), academic engagement dimensions (i.e., vigor, dedication and absorption) and academic performance, as well as the mediating role of academic engagement dimensions in the relationship between coping and academic performance. Data were collected from a sample of 808 undergraduate students at a Spanish University. Participants completed the Coping Strategies Inventory (CSI) for the measurement of coping strategies and the Work Engagement Student Scale (UWES-SS) for the measurement of academic engagement. Academic performance was evaluated by the grade point average. Results showed that adaptive coping, academic engagement dimensions and academic performance were positively related. Maladaptive coping was negatively related to performance, but there were no significant correlations between maladaptive coping and any academic engagement dimension. Mediation analysis showed that engagement dimensions mediated the relationship between adaptive coping and performance. Adaptive coping increased academic vigor, dedication and absorption and these dimensions improved performance in turn. In conclusion, this study provides evidence of the way in which academic engagement mediates between adaptive coping and performance. In addition, maladaptive coping is directly, negatively related to performance. The theoretical interpretation of the results and the potential applications for intervention are discussed.
\end{abstract}

Keywords: Coping strategies; Academic engagement; Performance; University students

\footnotetext{
${ }^{1}$ Correspondence: Olga Arias-Gundín, Universidad de León, Dpto. Psicología, Sociología y Filosofía, Facultad de Educación, Campus de Vegazana, S/N, 24071, León, Spain. E-mail: o.arias.gundin@unileon.es
} 


\section{Introduction}

In recent years, there has been an increase in research concerned with the benefits of student strengths, positive emotions and well-being on psychological adjustment to higher education and satisfactory academic results (Bailey \& Phillips, 2016; Turner, Holdsworth, \& Scott-Young, 2017). One of the most important skills for improving adjustment and success in university students is the ability to cope with the stress associated with academic challenges and demands (Gallego, Aguilar-Parra, Cangas, Rosado, \& Langer, 2016; Salanova, Schaufeli, Martinez, \& Bresó, 2010; Morosanu, Handley, \& O’Donovan, 2010; Robins, Roberts, \& Sarris, 2018). Another important characteristic related to adequate performance and achievement in higher education is academic engagement, or passion for learning (Bresó, Schaufeli, \& Salanova, 2011; Casuso-Holgado et al., 2013; Gasiewski, Eagan, Garcia, Hurtado, \& Chang, 2012; Oriol-Granado, Mendoza-Lira, Covarrubias-Apablaza, \& Molina-López, 2017; Pike, Smart, \& Ethington, 2012; Schaufeli, Martínez, Pinto, Salanova, \& Bakker, 2002). This study focuses on evaluating the relationship between coping strategies, academic engagement and performance in university students to design practical interventions.

The construct of coping was described by Folkman and Lazarus (1980) as the cognitive and behavioral reactions employed to tolerate or manage stressful demands perceived as exceeding personal abilities. Tobin, Holroyd, Reynolds, and Wigal (1989) specified that coping could be organized into two general categories; 'coping activities that engage the individual with, and coping activities that disengage the individual from, the stressful situation' (p. 355). They distinguished four specific engaged coping strategies: problem solving, cognitive restructuring, social support, and expressing emotions. Four specific disengaged coping strategies could also be employed: problem avoidance, wishful thinking, self-criticism and social withdrawal. Recently, active engaged coping strategies have been thought of as adaptive coping while avoidance disengaged coping strategies were maladaptive coping (Sagone \& De Caroli, 2014; Jauregui, Onaindia, \& Estévez, 2017).

In the context of higher education, adaptive coping has been associated with emotional intelligence (Thomas, Cassady, \& Heller, 2017), motivation (Struthers, Perry, \& Menec, 2000), optimism (Perera \& Mcllveen, 2014), satisfaction with the chosen career (Tartas et al., 2016) and positive commitment to studies (Bonneville-Roussy, Evans, Verner-Filion, Vallerand, \& Bouffard, 2017), while maladaptive coping has been 
associated with low levels of life satisfaction (Saklofske, Austin, Mastoras, Beaton, \& Osborne, 2012), negative affect and stress among university students (BonnevilleRoussy et al., 2017). In addition, previous research suggested that adaptive coping strategies are associated with academic performance (Saadu \& Adesokan, 2013; Schellenberg \& Bailis, 2016), whereas avoidant maladaptive coping strategies are associated with poorer academic achievement (MacCann, Fogarty, Zeidner, \& Roberts, 2011). However, previous research has suggested that the relationship between coping and performance may be mediated by other variables. In this regard, Crego, CarrilloDíaz, Armfield and Romero (2016) established that perceived stress mediated the relationship between coping and performance. Similarly, Ortega-Maldonado and Salanova (2018) found that meaning-focus coping was indirectly related to performance through academic satisfaction. Therefore, there is no clear evidence for a direct relationship between performance and coping. For that reason, this study evaluates the relationship, direct or indirect, between coping and academic performance.

Another emerging topic in higher education research is academic engagement. Conceptually, academic engagement has been described as a 'positive, fulfilling, workrelated state of mind that is characterized by vigor, dedication, and absorption' (Schaufeli et al., 2002, p. 74). In particular, vigor denotes high levels of energy and mental hardiness while studying, the perseverance and enthusiasm to invest time, even in the face of problems. Dedication refers to being intensely involved in study and feeling a sense of significance, inspiration, pride and challenge. Finally, absorption is characterized by concentrating fully and being joyfully immersed in work so that time passes quickly and even finding it difficult to detach oneself from academic tasks. Thus, students may feel motivated and engaged because they are flourishing and have achieved their objectives (Salanova et al., 2010). Therefore, academic engagement refers to a persistent affective and cognitive state of contentment toward studying and learning, rather than a momentary and specific condition (Salanova et al., 2010; Schaufeli et al., 2002).

There is evidence for a positive relationship between academic engagement and positive personal variables, including positive emotions (Oriol, Amutio, Mendoza, Da Costa, \& Miranda, 2016) and subjective well-being (Serrano \& Andreu, 2016). Previous research has also found that academic engagement was related to academic efficacy (Bresó et al., 2011; Durán, Extremera, Rey, Fernández-Berrocal, \& Montalbán, 2006) and adaptability to the course of study (Merino-Tejedor, Hontangas, \& Boada-Grau, 
2016). Academic engagement has also been found to be associated with academic performance (Casuso-Holgado et al., 2013; Manzano, 2002; Oriol-Granado et al., 2017; Salanova et al., 2010; Schaufeli et al., 2002; Serrano \& Andreu, 2016; Spedding, Hawkes, \& Burgess, 2017). However, to date there is no consensus regarding the relationship between each of the academic engagement dimensions and academic performance. For example, Serrano \& Andreu (2016) found a positive association between academic achievement and the three engagement dimensions (i.e., vigor, dedication and absorption) in a sample of adolescents, and Salanova et al. (2010) found that academic performance was related to vigor and dedication in university students. However, Manzano (2002) established that only dedication predicted academic achievement in university students. In contrast, Casuso-Holgado et al. (2013) found that academic achievement was related to vigor and absorption, but not to dedication. Finally, other studies have linked academic engagement and performance, considering engagement to be a unidimensional construct (Oriol-Granado et al., 2017; Spedding et al., 2017). Therefore, the current study evaluates the relationship between the three engagement dimensions and academic performance.

There is little current research directly addressing engagement and coping. Previous studies suggested that work engagement was positively related to proactive, problemfocused and approach coping in teachers, firefighters and nurses respectively (Ângelo \& Chambel, 2014; Parker, Martin, Colmar, \& Liem, 2012; Van der Colff \& Rothmann, 2009). In contrast, teacher work engagement was negatively related to emotion-focused or maladaptive coping (Parker et al., 2012). Besides, academic engagement was found to be related to positive reframing coping in adolescents (Robins, Roberts, \& Sarris, 2015) and to future-oriented coping in college students (Gan, Yang, Zhou, \& Zhang, 2007). Some studies along these lines have shown a positive association between emotional intelligence and academic engagement dimensions (Durán et al., 2006; Extremera, Durán, \& Rey, 2007). They suggested that emotional intelligence reflects the capacity to regulate emotions and in the same way adaptive coping strategies are aimed at managing or regulate stressors. To continue on from that research, this current study also examines the possible relationships between coping and academic engagement dimensions.

Finally, according to the engagement model proposed by Bakker and Demerouti (2007), some resources influence performance by affecting engagement. For example, resilience and optimism, being personal resources, create a motivational process leading 
to engagement and, thus, improve performance (Bakker \& Demerouti, 2008; Bakker, 2011). Similarly, various studies have reported the mediating effect of academic engagement in the relationship between academic performance and different resources such as perceived emotional intelligence (Serrano \& Andreu, 2016), positive emotions (Oriol-Granado et al., 2017) and self-efficacy (Ouweneel, Schaufeli, \& Le Blanc, 2013). Therefore, if adaptive coping is a personal resource for managing stressful situations, it could be related to performance through academic engagement dimensions. Previous research suggested that performance was indirectly and positively related to adaptive coping (Crego et al., 2016; Struthers et al., 2000; Ortega-Maldonado \& Salanova, 2018) but it was indirectly and negatively related to maladaptive emotional coping (Crego et al., 2016). The current study evaluates the possible mediating role of academic engagement in the relationship between coping and academic performance.

In short, several studies have reported that both coping and academic engagement are related to academic performance. However, the relationship between each specific academic engagement dimension and academic performance remains unclear. Furthermore, there is no evidence of the relationship between coping strategies and the academic engagement dimensions. In addition, no studies have simultaneously considered the relationships of both academic engagement and coping with academic performance. Identifying the relationships between academic performance and personal resources and academic engagement could be used for designing effective interventions to improve performance among university students. Therefore, the aim of the present study was to examine the relationship between coping strategies, academic engagement dimensions and academic performance, and also the mediating effect of engagement dimensions in the relationship between coping and performance. The hypotheses of the present study are formulated as follows:

$\mathrm{H}_{1}$. Adaptive coping will be positively correlated with performance whereas maladaptive coping will be negatively correlated with performance.

$\mathrm{H}_{2}$. Adaptive coping will be positively correlated with academic engagement dimensions whereas maladaptive coping will be negatively correlated with academic engagement dimensions.

$\mathrm{H}_{3}$. Academic engagement dimensions will be positively correlated with performance.

$\mathrm{H}_{4}$. Academic engagement dimensions will positively mediate the relationship between coping strategies and academic performance. 


\section{Method}

\section{Participants}

The convenience sample consisted of 808 Spanish undergraduate students $(76.5 \%$ female and $23.5 \%$ male). They were studying toward various undergraduate degrees at the University of León: Infant Education (31.9\%), Primary Education (34.2\%), Social Education (16.7\%), and Labour Relations and Human Resources (17.2\%). Of the total sample, $27.7 \%$ were in their first year, $23.2 \%$ in their second, $31.3 \%$ in their third and $17.8 \%$ in their fourth. The mean age of the sample was 21.72 years old $(D T=3.46)$.

\section{Procedure}

The study was performed during the second academic semester, so that first-year students could provide informed answers to questions about how engaged they were in studying and they would be able to report their first semester's academic performance. The data was always collected with the consent of the teacher. Students were approached in their own classes and they agreed to participate voluntarily. They answered a confidential, anonymous battery of questionnaires. A psychologist who was present during the session answered any questions the students may have had.

\section{Measures}

\section{Coping Strategies}

The participants' coping strategies were assessed using the Coping Strategies Inventory (CSI) originally created by Tobin et al. (1989) and adapted to a Spanish context by Jauregui, Herrero-Fernández and Estévez (2016). It consists of 40 items about various coping strategies that may be used to manage or tolerate stressful situations. Eight Coping strategies with 5 items each can be organized into general Coping dimensions. The Coping strategies are as follows: (1) Problem solving (e.g., 'I worked on solving the problems in the situation'), (2) Cognitive restructuring (e.g., 'I convinced myself that things aren't quite as bad as they seem'), (3) Expressing emotions (e.g., 'I got in touch with my feelings and just let them go'), (4) Social support (e.g., 'I found somebody who was a good listener'), (5) Problem avoidance (e.g., 'I avoided thinking or doing anything about the situation'), (6) Wishful thinking (e.g., 'I wished that the 
situation would go away or somehow be over with'), (7) Self-criticism (e.g., 'I blamed myself'), and (8) Social withdrawal (e.g., 'I avoided being with people'). The two general coping dimensions are adaptive coping strategies (strategies 1, 2, 3 and 4) and maladaptive coping strategies (strategies 5, 6, 7 and 8). Responses are given on a fivepoint Likert-type scale ranging from 1 (not at all) to 5 (very much). Jauregui et al. (2016) reported Cronbach's alpha of 90 (adaptive coping) and .87 (maladaptive coping).

\section{Academic Engagement}

Academic engagement was measured through the Spanish version of the Work Engagement Student Scale (UWES-SS) created by Schaufeli et al. (2002). The scale consists of 17 items which evaluate three dimensions: vigor, with 6 items (e.g., 'When I'm doing my work as a student, I feel bursting with energy'); dedication, with 5 items (e.g., 'I am enthusiastic about my studies'), and absorption, with 6 items (e.g., 'Time flies when I'm studying'). Participants indicate the level of agreement with each item on a seven-point Likert response scale from 0 (never) to 6 (always). High scores on the three dimensions are indicative of higher levels of academic engagement. Originally, Schaufeli et al. (2002) reported Cronbach's alpha of .79 (vigor), .85 (dedication) and .65 (absorption).

\section{Academic Performance}

Finally, the students' academic performance was measured by the cumulative grade point average (GPA) over their college experience to date. Consistent with the Spanish system of qualifications, GPA ranged from 5 (low) to 10 (high). This data was self reported by students.

\section{Data analyses}

First of all, the multivariate normal distribution was assessed, testing that all variables had kurtosis indices no greater than \pm 7 and skew indices no greater than \pm 3 (Kline, 2011). Since the data showed that the assumption of normality was not violated (as seen in Table 1), all variables were used in the subsequent analyses. Cronbach's alpha coefficients were calculated to assess the internal reliability of scores. 
Table 1.

Means (M), standard deviations (SD), skewness (Sk), kurtosis (K) and Cronbach's alpha coefficients (a) of the variables in this study

\begin{tabular}{|c|c|c|c|c|c|c|c|}
\hline & Min & Max & M & SD & Sk & $\mathrm{K}$ & $A$ \\
\hline 1. Adaptive ${ }^{a}$ & 1.60 & 5.00 & 3.35 & .54 & -09 & $.2 \theta$ & .86 \\
\hline 2. Maladaptive & 1.10 & 4.70 & 2.89 & .50 & 18 & .35 & .80 \\
\hline 3. Viger ${ }^{b}$ & 17 & 6.00 & 2.84 & .87 & .37 & .27 & .65 \\
\hline 4. Dedication ${ }^{b}$ & .20 & 6.00 & 4.27 & 1.02 & .74 & .64 & .81 \\
\hline 5. Abserption ${ }^{b}$ & 17 & 5.67 & 2.85 & .85 & .44 & .32 & .68 \\
\hline 6. Performance & 5.00 & $9.4 \theta$ & 6.88 & .76 & .22 & .08 & - \\
\hline
\end{tabular}

${ }^{a}$ coping strategies; ${ }^{b}$-engagement dimensions

Pearson correlation coefficients were used to examine the relationships between coping (i.e., adaptive or maladaptive), academic engagement dimensions (i.e., vigor, dedication and absorption) and academic performance.

In addition, bootstrap mediation analysis was performed to evaluate the mediating role of academic engagement dimensions in the relationship between coping and academic performance. The bootstrapping method uses a resampling with replacement technique to generate a standard error of the mediation pathway, against which confidence intervals can be calculated (Hayes, 2013). The bootstrapping approach eliminates the assumption of the normality of the sampling distribution (Hayes, 2009; Preacher \& Hayes, 2004). The PROCESS macro for SPSS was used to test the mediation pathways (Hayes, 2013), downloadable from www.processmacro.org (Hayes, 2018). This macro computes the total and indirect effects of the independent variable on the dependent variable. For mediation models, total, direct, and indirect effects were calculated on the basis of 5,000 bootstrapped samples and bias-corrected and accelerated confidence intervals with $95 \%$ level of confidence. The estimation of the significance of indirect effects was assessed using the Sobel asymptotic $z$ test (Sobel, 1982) and confidence intervals that excluded zero. 
The following statistical programs were used: SPSS version 24, for the descriptive statistics and PROCESS version 2.11 (Hayes, 2012).

\section{Results}

\section{Reliability measures}

The means, standard deviations, Cronbach's alpha coefficients and correlations are shown in Table 1. Missing data were replaced by the mean in each variable. The preliminary analyses indicated that the skewness values for the measured variables ranged from -.74 to .41 and the kurtosis values ranged from -.20 to .64 . These results indicated that the normality assumption was met. In terms of internal consistency, both scales achieve good reliability in the different subscales used. In the Spanish version of the Work Engagement Student Scale (UWES-SS), Cronbach's alpha values were .65 (vigor), .81 (dedication) and .68 (absorption). For the Coping Strategies Inventory (CSI), Cronbach's alpha values were .86 for adaptive coping and .80 for maladaptive coping.

\section{Correlation analyses}

The Pearson correlations between academic engagement dimensions (i.e., vigor, dedication and absorption), academic performance and coping dimensions (i.e., adaptive and maladaptive) are shown in Table 1 . The results revealed that adaptive coping and maladaptive coping strategies were significantly and positively correlated. All correlations between the different academic engagement dimensions were positive and statistically significant. As expected, performance was positively correlated with adaptive coping but negatively correlated with maladaptive coping. In addition, all academic engagement dimensions were significantly and positively correlated with academic performance. Finally all academic engagement dimensions were significantly and positively correlated with adaptive coping but there were no significant correlations between maladaptive coping and any academic engagement dimension. 
Table 1.

Means (M), standard deviations (SD), Cronbach's alpha coefficients $(\alpha)$ and Pearson correlations for all the measured variables

\begin{tabular}{|c|c|c|c|c|c|c|c|c|}
\hline & M & $\mathrm{SD}$ & $\alpha$ & 1 & 2 & 3 & 4 & 5 \\
\hline 1. Adaptive ${ }^{a}$ & 3.35 & .54 & .86 & & & & & \\
\hline 2. Maladaptive ${ }^{a}$ & 2.89 & .50 & .80 & $.09^{*}$ & & & & \\
\hline 3. Vigor ${ }^{\mathrm{b}}$ & 2.84 & .87 & .65 & $.36^{* *}$ & -.01 & & & \\
\hline 4. Dedication ${ }^{\mathrm{b}}$ & 4.27 & 1.02 & .81 & $.33^{* *}$ & .02 & $.48^{* *}$ & & \\
\hline 5. Absorption ${ }^{\mathrm{b}}$ & 2.85 & .85 & .68 & $.33^{* *}$ & .03 & $.70^{* *}$ & $.55^{* *}$ & \\
\hline 6. Performance & 6.88 & .76 & -- & $.09^{*}$ & $-.16^{* *}$ & $.31^{* *}$ & $.17^{* *}$ & $.27^{* *}$ \\
\hline
\end{tabular}

$* p<.05 ; * * p<.01$.

${ }^{\mathrm{a}}$ coping strategies; ${ }^{\mathrm{b}}$ engagement dimensions.

Note: $\alpha=$ Cronbach's $\alpha$ coefficients.

\section{Mediation analyses}

The mediation model of academic engagement in the relationship between adaptive eoping and academic performance is illustrated in Figure 1. As there was no significant correlation between maladaptive coping and any academic engagement dimension, the mediation model was not tested for this case.

Figure 1 presents the mediational models examining the pathways between adaptive coping and academic performance through the academic engagement variables of Vigour, Dedication and Abortion. As there was no significant relationship between maladaptive coping and any of the academic engagement variables, these mediational models were not examined. 

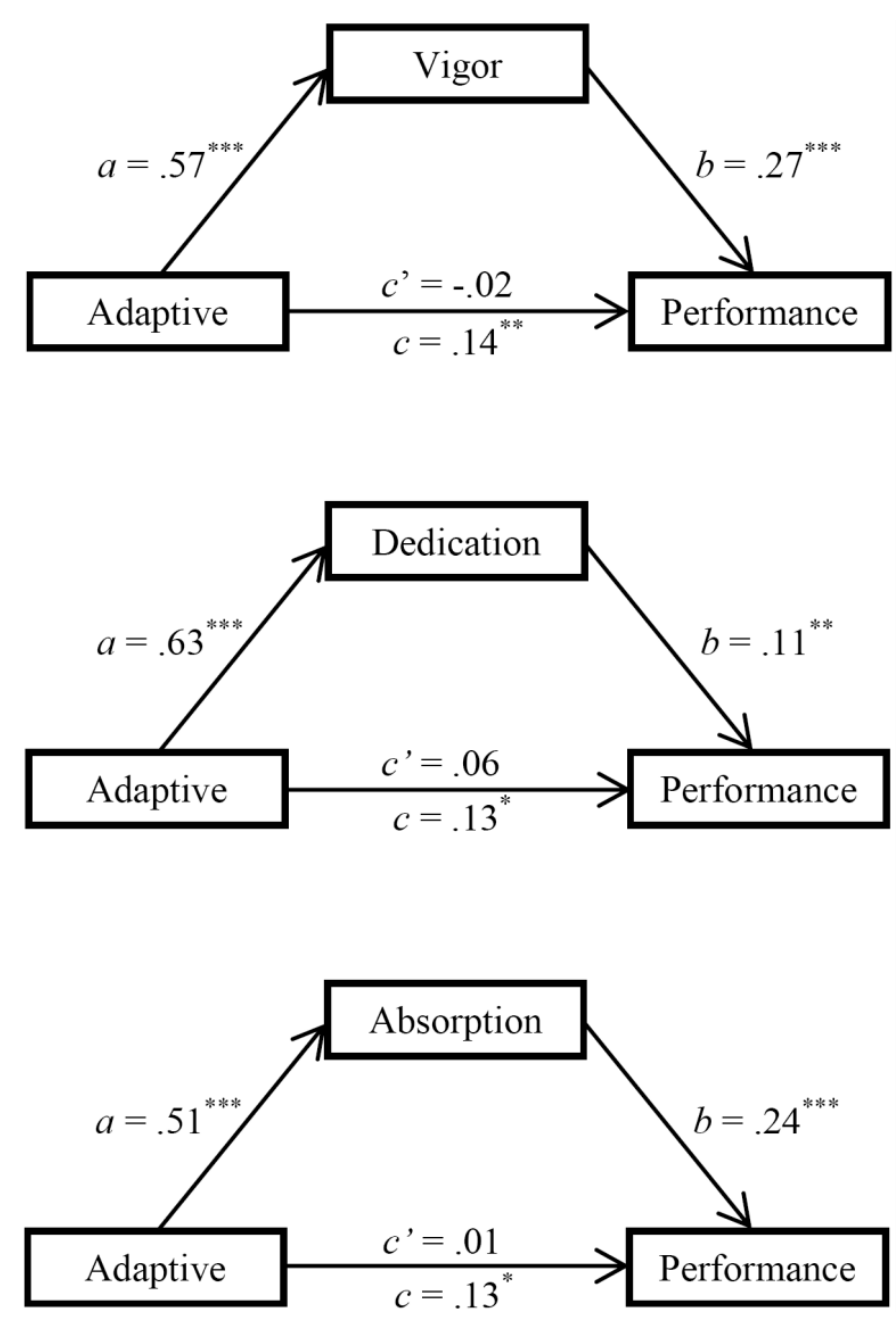

Figure 1.

A mediation model of academic engagement in the relationship between adaptive coping and academic performance $(* \mathrm{p}<.05 ; * * \mathrm{p}<.01 ; * * * \mathrm{p}<.001)$

The mediating role of vigor between adaptive coping and performance is presented in Figure 1. The total effect of adaptive coping on performance was significant $(t=$ $2.59, p<.01 ; c$ path). Adaptive coping also had a significant effect on vigor $(t=10.11$, $p<.001 ; a$ path $)$ as did vigor on academic performance $(t=8.32, p<.001 ; b$ path). Since the bootstrapped $95 \%$ confidence interval did not contain zero $(.11, .21)$, the indirect effect was significant. After controlling for the effect of vigor, the effect of adaptive coping on academic performance was not significant $\left(t=-.35, p=.72 ; c^{\prime}\right.$ path), meaning full mediation.

The mediating role of dedication between adaptive coping and performance is also shown in Figure 1. The total effect of adaptive coping on performance was significant $(t$ 
$=2.39, p<.05 ; c$ path). There was a significant effect of adaptive coping on dedication $(t=9.47, p<.001 ; a$ path $)$ and of dedication on academic performance $(t=3.88, p<$ $.01 ; b$ path). The botstrapped $95 \%$ confidence interval did not contain zero $(.03, .11)$, so the indirect effect was significant. The indirect effect was confirmed to be significant, by the confidence of interval of bootstrapping $(.03, .11)$. The main effect of adaptive coping on academic performance was not significant after controlling for the effect of dedication ( $t=1.01, p=.31 ; c^{\prime}$ path), suggesting full mediation.

Finally, the mediating role of absorption between adaptive coping and performance is presented in Figure 1. The total effect of adaptive coping on performance was significant $(t=2.49, p<.05 ; c$ path). There was also a significant effect of adaptive coping on absorption $(t=9.20, p<.001 ; a$ path $)$ and of absorption on academic performance $(t=7.19, p<.001 ; b$ path). The eonfidence interval between .09 and .17 confirmed that the indirect effect was significant. The effect of adaptive coping on academic performance was not significant after controlling for the effect of absorption $\left(t=.14, p=.89 ; c^{\prime}\right.$ path $)$, signifying full mediation.

Table 2.

Mediational Model of the engagement dimensions in the relationship between adaptive and academic performance

\begin{tabular}{llcccccc}
\hline $\begin{array}{l}\text { Independent } \\
\text { variable }\end{array}$ Mediators & $\begin{array}{c}\text { Dependent } \\
\text { variable }\end{array}$ & $\beta$ & SE & $\begin{array}{c}\text { Confidence } \\
\text { interval (CI) }\end{array}$ & $z$ & $p$ \\
\hline Adaptive $\rightarrow$ Vigor & $\rightarrow$ Performance & .16 & .02 & .11 & .21 & 6.40 & .0000 \\
Adaptive $\rightarrow$ Dedication $\rightarrow$ Performance & .07 & .02 & .03 & .11 & 3.58 & .0003 \\
Adaptive $\rightarrow$ Absorption $\rightarrow$ Performance & .12 & .02 & .09 & .17 & 5.65 & .0000 \\
\hline
\end{tabular}

In short, as Table 2 shows, the results indicate that academic engagement dimensions significantly and positively mediated the effect of adaptive coping on academic performance. 


\section{Discussion}

This study evaluated the relationships between coping strategies, academic engagement dimensions and academic performance by conducting correlation and mediation analyses. The expectation was that adaptive coping would be positively correlated with academic performance while maladaptive coping would be negatively correlated with academic performance and that academic engagement dimensions would mediate the relationship between coping strategies and academic performance. Overall, the results provide evidence in support of several of these hypotheses.

Firstly, the results show that adaptive coping was significantly and positively correlated with performance. This result agrees with previous research demonstrating that students who can cope with stressors may reach higher levels of academic achievement (Saadu \& Adesokan, 2013; Schellenberg \& Bailis, 2016). Maladaptive coping was also expected to be negatively related to academic performance. The results verify that students who avoid stressful situations and problems exhibit poorer academic performance, in line with past research (MacCann et al., 2011). In short, these findings reinforce the importance of educational interventions to advise university students about the negative effects of avoidant maladaptive coping and to train them to develop adaptive coping skills.

The results also showed that academic engagement was significantly and positively correlated with academic performance. Specifically, vigor, dedication and absorption were positively related to performance. According to some research, students who show high levels of engagement with their studies achieve better academic performance (Casuso-Holgado et al., 2013; Manzano, 2002; Oriol-Granado et al., 2017; Salanova et al., 2010; Schaufeli et al., 2002; Serrano \& Andreu, 2016; Spedding et al., 2017). In order to explain this result, it may be useful to remember that vigor denotes mental hardiness, dedication refers to involvement in studies and absorption refers to concentration while studying; in other words, each dimension is related to the intense effort required to study in higher education. Therefore, since academic engagement is a motivational factor that has a positive influence on academic performance, this study demonstrates the importance of stimulating university students to encourage their academic success.

Coping was significantly and positively correlated with academic engagement. In particular, vigor, dedication and absorption were related to adaptive coping. This result 
is consistent with findings of previous research using correlational and hierarchical regression analyses. Robins et al. (2015) pointed out that unidimensional engagement was predicted by the positive reframing coping style in university students. They concluded that personal resources are essential in predicting engagement. Similarly, previous studies demonstrated a positive association between the ability to cope with emotions (i.e., emotional intelligence) and academic engagement (Durán et al., 2006; Extremera et al., 2007; Serrano \& Andreu, 2016). This finding has implications for interventions; it is essential to design programs to train university students in using active, efficient and functional coping strategies (i.e., problem solving, cognitive restructuring, expressing emotions and social support) which would help them to manage stressful situations related to higher education. Moreover, these adaptive coping strategies might increase their mental hardiness, inspiration and concentration while studying. Regarding maladaptive coping, it was expected to be negatively related to academic engagement because previous research found that work engagement was negatively related to maladaptive coping among workers (Parker et al., 2012). The results did not confirm this hypothesis; there were no significant correlations between maladaptive coping and any academic engagement dimension. This result is relevant because it reveals that maladaptive coping does not necessarily reduce academic engagement among university students while adaptive coping appears to foster engagement. Further research is needed to clarify the relationship of academic engagement and maladaptive coping.

Finally, mediation analysis showed that the engagement dimensions mediated the relationship between adaptive coping and academic performance. Adaptive coping increased academic vigor, dedication and absorption and these three dimensions increase performance. This result is consistent with the engagement model proposed by Bakker and Demerouti (2007). According to that model, resources affect engagement and this, in turn, facilitates better performance (Bakker \& Demerouti, 2008; Bakker, 2011). Previous research reported that academic engagement mediates the relationship between academic performance and resources such as emotional intelligence, positive emotions and self-efficacy (Oriol-Granado et al., 2017; Ouweneel, Schaufeli, \& Le Blanc, 2013; Serrano \& Andreu, 2016). Similarly, adaptive coping could be considered to be a personal resource which improves academic performance through increasing academic engagement. Those students who are able to manage stressful situations feel stronger, more involved and immersed in their studies, which may enhance their 
academic performance. Moreover, the current results agree with the Conservation of Resources (COR) theory, which proposes that 'during highly stressful circumstances, resource gain cycles are most likely to emerge as people seek to identify and mobilize resources' (Hobfoll, 2002, p. 315). The COR theory also suggests that resources (e.g., resilience, self-esteem and attention) are linked to other resources so having resources promotes further accumulation of resources (Hobfoll, 2002; Hobfoll, Halbesleben, Neveu, \& Westman, 2018). In this regard, academic engagement could be cosidered as a motivational resource since it may be described as the degree to which students feel mentally and emotionally competent to face academic demands (Lorente, Salanova, Martínez, \& Schaufeli, 2008). Specifically, vigor may denote high levels of mental energy and resilience resources while studying, dedication may involve pride and selfesteem resources, and absorption may be characterized by enjoyment and attention resources. Thus, since adaptive coping increased academic engagement dimensions which enhanced performance, it may be conclude that performance could be the result of accumulating or adding coping resources to academic motivational resources.

In contrast, since maladaptive coping was not related to engagement, the results do not support the existence of a mediating role for engagement in the relationship between maladaptive coping and performance. Therefore, maladaptive coping does not necessarily inhibit academic engagement. However, the relationship between maladaptive coping and performance could be mediated by other variables. For example, maladaptive coping has been previously associated with academic burnout among adolescents (Luo, Wang, Zhang, Chen, \& Quan, 2016). One interesting topic for future research is the possibility that academic burnout could mediate the relationship between maladaptive coping and academic performance in university students.

Therefore, maladaptive coping is directly related to performance while adaptive eoping has an indirect relationship. Recently, Bonneville-Roussy et al. (2017) found that maladaptive coping played a far greater role than adaptive coping in outcomes for university students. For this reason, the direct effect of maladaptive coping on academic performance found in this study may be attributed to its greater importance in student achievement than that of adaptive coping. In summary, coping skills promote positive attitudes towards studying and learning in university students and indirectly improve their academic success, while coping incompetence is not related to academic engagement but negatively affects academic performance. 


\section{Implications}

This study could have important implications for research linking academic engagement and academic performance (Casuso-Holgado et al., 2013; Manzano, 2002; OriolGranado et al., 2017; Salanova et al., 2010; Schaufeli et al., 2002; Serrano \& Andreu, 2016; Spedding et al., 2017). In addition, this study extends previous research suggesting a mediated relationship between coping and performance (Crego et al., 2016; Ortega-Maldonado and Salanova, 2018). Specifically, the results indicate the relevance of considering engagement dimensions as personal resources that mediates between coping resources and academic performance among university students. Therefore, the current study confirms the assumption of the engagement model that personal resources influence performance by affecting engagement (Bakker \& Demerouti, 2007, 2008; Bakker, 2011) and agrees with the COR theory, which proposes that resources are linked to other resources operating in the service of adjustment.

These results provide useful evidence to design effective interventions oriented to improve academic performance. Thus, intervention programs should be designed to promote adaptive coping strategies in university students in order to enhance academic engagement and, therefore, improve performance. In this regard, Bresó et al. (2011) established the effectiveness of self-efficacy-based intervention programs for developing coping skills and promoting engagement and well-being in university students in order to improve academic performance. In the same way, BonnevilleRoussy et al. (2017) identified the need to create programs which provide university students with engagement-adaptive coping strategies. It is especially important to implement this kind of interventions to develop coping, engagement and, therefore, performance among students in Spanish universities, which are focused on the promotion of students' engagement, motivation, and autonomy, attending the educational paradigm fostered by the Bologna Process (Keeling, 2006; RoblesFernández, Pedrosa, Suárez-Álvarez, Blanco-Saldaña, \& García-Cueto, 2017; Rosário et al., 2015).

\section{Limitations and suggestions for future research}

It is important to note that the sample group used was studying toward four different degrees (Infant Education, Primary Education, Social Education, and Labour Relations and Human Resources). More research is needed with larger sample sizes, including 
students from more diverse university degrees. Next, since the students in the study were mostly women, future studies must include more male students in order to offer more generalizable findings and assess possible gender differences. In addition, the GPA data was self reported by students and self-reported measures could increase the risk of common method biases (e.g., social desirability). Thus, future research should evaluate performance by the GPA values just provided by the University. Besides, it is difficult to infer the causal relationship between the variables in the study, because it was only considered statistical mediation. Finally, future research could propose and evaluate innovative intervention programs to train active and effective coping strategies to improve academic engagement and performance in university students.

\section{Conclusions}

In conclusion, this study evaluates the relationship between coping, academic engagement and performance in university students and uses mediation analysis to evaluate the mediating role of academic engagement dimensions in the relationship between coping and performance. The results show that adaptive coping positively affects academic engagement dimensions, engagement positively influences academic performance and maladaptive coping negatively affects academic performance. Moreover, the results show that adaptive coping improves academic performance through increasing academic engagement dimensions. This research provides significant outcomes that could be employed to design counseling programs to enhance university students' coping competences, academic engagement and performance.

\section{References}

Ângelo, R. P., \& Chambel, M. J. (2014). The role of proactive coping in the job demands-resources model: A cross-section study with firefighters. European Journal of Work and Organizational Psychology, 23(2), 203-216. doi: $\underline{10.1080 / 1359432 X .2012 .728701}$

Bailey, T. H., \& Phillips, L. J. (2016). The influence of motivation and adaptation on students' subjective well-being, meaning in life and academic performance. Higher Education Research \& Development, 35(2), 201-216. doi: $\underline{10.1080 / 07294360.2015 .1087474}$ 
Bakker, A. B. (2011). An evidence-based model of work engagement. Current

Direction in Psychological Science, 20(4), 265-269. doi:

$\underline{10.1177 / 0963721411414534}$

Bakker, A. B., \& Demerouti, E. (2008). Towards a model of work engagement. Career Development International, 13(3), 209-223. doi: 10.1108/13620430810870476

Bakker, A. B., \& Demerouti, E. (2007). The job demands-resources model: State of the art. Journal of Managerial Psychology, 22(3), 309-328. doi:

$\underline{10.1108 / 02683940710733115}$

Bonneville-Roussy, A., Evans, P., Verner-Filion, J., Vallerand, R. J., \& Bouffard, T. (2017). Motivation and coping with the stress of assessment: Gender differences in outcomes for university students. Contemporary Educational Psychology, 48, 28-42. doi: 10.1016/j.cedpsych.2016.08.003

Bresó, E., Schaufeli, W. B., \& Salanova, M. (2011). Can a self-efficacy-based intervention decrease burnout, increase engagement, and enhance performance? A quasi-experimental study. Higher Education, 61(4), 339-355. doi: 10.1007/s10734$\underline{010-9334-6}$

Casuso-Holgado, M. J., Cuesta-Vargas, A. I., Moreno-Morales, N., LabajosManzanares, M. T., Barón-López, F. J., \& Vega-Cuesta, M. (2013). The association between academic engagement and achievement in health sciences students. BMC Medical Education, 13: 33. doi: 10.1186/1472-6920-13-33

Crego, A., Carrillo-Díaz, M., Armfield, J. M., \& Romero, M. (2016). Stress and academic performance in dental students: The role of coping strategies and examination-related self-efficacy. Journal of Dental Education, 80, 165-172.

Durán, A., Extremera, N., Rey, L., Fernández-Berrocal, P., \& Montalbán, F. M. (2006). Predicting academic burnout and engagement in educational settings: Assessing the incremental validity of perceived emotional intelligence beyond perceived stress and general self-efficacy. Psicothema, 18, 158-164.

Extremera, N., Durán, A., \& Rey, L. (2007). Emotional intelligence and its relationship with the levels of burnout, engagement and stress in university students. Revista de Educación, 342, 239-256.

Folkman, S., \& Lazarus, R. S. (1980). Coping as a mediator of emotion. Journal of Personality and Social Psychology, 54(3), 466-475. doi: 10.1037/0022$\underline{3514.54 .3 .466}$ 
Gallego, J., Aguilar-Parra, J. M., Cangas, A. J., Rosado, A., \& Langer, A. I. (2016). Effect of mind/ body interventions on levels of anxiety, stress and depression among future primary school teacher: A controlled study. Journal of Psychodidactics, 21(1), 87-101. doi: 10.1387/RevPsicodidact.13256

Gan, Y., Yang, M., Zhou, Y., \& Zhang, Y. (2007). The two-factor structure of futureoriented coping and its mediating role in student engagement. Personality and Individual Differences, 43, 851-863. doi: 10.1016/j.paid.2007.02.009

Gasiewski, J. A., Eagan, M. K., Garcia, G. A., Hurtado, S., \& Chang, M. J. (2012). From gatekeeping to engagement: A multicontextual, mixed method study of student academic engagement in introductory STEM courses. Research in Higher Education, 53(2), 229-261. doi: 10.1007/s11162-011-9247-y

Hayes, A. F. (2009). Beyond Baron and Kenny: Statistical mediation analysis in the new millennium. Communication Monographs, 76(4), 408-420. doi: $\underline{10.1080 / 03637750903310360}$

Hayes, A. F. (2012). PROCESS: A versatile computational tool for observed variable mediation, moderation, and conditional process modeling. [White paper]. Retrieved from http://www.afhayes.com/public/process2012.pdf

Hayes, A. F. (2013). Introduction to mediation, moderation, and conditional process analysis: A regression-based approach. New York: Guilford Press.

Hayes, A. F. (2018). Partial, conditional, and moderated moderated mediation: Quantification, inference, and interpretation, Communication Monographs, 85(1), 440. doi: $\underline{10.1080 / 03637751.2017 .1352100}$

Hobfoll, S. E. (2002). Social and psychological resources and adaptation. Review of General Psychology, 6(4), 307-324. doi: 10.1037//1089-2680.6.4.307

Hobfoll, S. E., Halbesleben, J., Neveu, J. P., \& Westman, M. (2018). Conservation of resources in the organizational context: The reality of resources and their consequences. Annual Review of Organizational Psychology and Organizational Behavior, 5, 103-128. doi: 10.1146/annurev-orgpsych-032117-104640

Jauregui, P., Herrero-Fernández, D. \& Estévez, A. (2016). Estructura factorial del "Inventario de Estrategias de Afrontamiento" y su relación con la regulación emocional, ansiedad y depresión. Behavioral Psychology, 24(2), 319-340.

Jauregui, P., Onaindia, J., \& Estévez, A. (2017). Adaptive and Maladaptive coping strategies in adult pathological gamblers and their mediating role with anxious- 
deressive symptomatology. Journal of Gambling Studies, 33(4), 1-17. doi: $\underline{10.1007 / \mathrm{s} 10899-017-9675-5}$

Keeling, R. (2006). The Bologna process and the Lisbon research Agenda: The European commission's expanding role in higher education discourse. European Journal of Education, 41(2), 203-223.

Kline, R. B. (2011). Convergence of structural equation modeling and multilevel modeling. In M. Williams, \& W. P. Vogt (Eds.), Handbook of methodological innovation in social research methods (pp.562-589). London: Sage.

Lorente, L., Salanova, M., Martínez, I., \& Schaufeli, W. (2008). Extension of the Job Demands-Resources model in the prediction of burnout and engagement among teachers over time. Psicothema, 20(3), 354-360.

Luo, Y., Wang, Z., Zhang, H., Chen, A., \& Quan, S. (2016). The effect of perfectionism on school burnout among adolescence: The mediator of self-esteem and coping style. Personality and Individual Differences, 88, 202-208. doi:

$\underline{10.1016 / j . p a i d .2015 .08 .056}$

MacCann, C., Fogarty, G. J., Zeidner, M., \& Roberts, R. D. (2011). Coping mediates the relationship between emotional intelligence (EI) and academic achievement. Contemporary Educational Psychology, 36(1), 60-70. doi: 10.1016/j.cedpsych.2010.11.002

Manzano, G. (2002). Burnout and engagement. Their relations with students' accomplishment, professional maturity and dropout tendency. International Journal of Social Psychology, 17(3), 237-249. doi: 10.1174/02134740260372973

Merino-Tejedor, E., Hontangas, P. M., \& Boada-Grau, J. (2016). Career adaptability and its relation to self-regulation, career construction, and academic engagement among Spanish university students. Journal of Vocational Behavior, 93, 92-102. doi: 10.1016/j.jvb.2016.01.005

Morosanu, L., Handley, K., \& O’Donovan, B. (2010). Seeking support: researching first-year students' experiences of coping with academic life. Higher Education Research \& Development, 29(6), 665-678. doi: 10.1080/07294360.2010.487200

Oriol, X, Amutio, A., Mendoza, M., Da Costa, S., \& Miranda, R. (2016). Emotional creativity as predictor of intrinsic motivation and academic engagement in university students: The mediating role of positive emotions. Frontiers in Psychology, 7: 1243. doi: $\underline{10.3389 / \text { fpsyg.2016.01243 }}$ 
Oriol-Granado, X., Mendoza-Lira, M., Covarrubias-Apablaza, C. G., \& Molina-López, V. (2017). Positive emotions, autonomy support and academic performance of university students: The mediating role of academic engagement and self-efficacy. Journal of Psychodidactics, 22(1), 45-53. doi: 10.1387/RevPsicodidact.14280

Ortega-Maldonado, A., \& Salanova, M. (2018). Psychological capital and performance among undergraduate students: the role of meaning-focused coping and satisfaction. Teaching in Higher Education, 23(3), 390-402. doi: $\underline{10.1080 / 13562517.2017 .1391199}$

Ouweneel, E., Schaufeli, W. B., \& Le Blanc, P. M. (2013). Believe, and you will achieve: Changes over time in self-efficacy, engagement, and performance. Applied Psychology: Health and Well-Being, 5(2), 225-247. doi: 10.1111/aphw.12008

Parker, P. D., Martin, A. J., Colmar, S., \& Liem, G. A. (2012). Teachers' workplace well-being: Exploring a process model of goal orientation, coping behavior, engagement, and burnout. Teaching and Teacher Education, 28(4), 503-513. doi: $\underline{10.1016 / j . t a t e .2012 .01 .001}$

Perera, H. N., \& McIlveen, P. (2014). The role of optimism and engagement coping in college adaptation: A career construction model. Journal of Vocational Behavior, 84(3), 395-404. doi: 10.1016/j.jvb.2014.03.002

Pike, G. R., Smart, J. C., \& Ethington, C. A. (2012). The mediating effects of student engagement on the relationships between academic disciplines and learning outcomes: An extension of Holland's Theory. Research in Higher Education, 53(5), 550-575. doi: 10.1007/s11162-011-9239-y

Preacher, K. J., \& Hayes, A. F. (2004). SPSS and SAS procedures for estimating indirect effects in simple mediation models. Behavior Research Methods, Instruments, \& Computers, 36(4), 717-731. doi: 10.3758/BF03206553

Robins, T. G., Roberts, R. M., \& Sarris, A. (2015). Burnout and engagement in health profession students: The relationships between study demands, study resources and personal resources. Australasian Journal of Organisational Psychology, 8, 1-13. doi: 10.1017/orp.2014.7

Robins, T. G., Roberts, R. M., \& Sarris, A. (2018). The role of student burnout in predicting future burnout: exploring the transition from university to the workplace. Higher Education Research \& Development, 37(1), 115-130. doi: $\underline{10.1080 / 07294360.2017 .1344827}$ 
Robles-Fernández, A., Pedrosa, I., Suárez-Álvarez, J., Blanco-Saldaña, I., \& GarcíaCueto, E. (2017). Cambio de plan y calidad educativa [Curricular change and educational quality]. Cultura y Educación, 29(1), 97-119. doi: $\underline{10.1080 / 11356405.2016 .1269503}$

Rosário, P., Núñez, J. C., Trigo, L., Guimarães, C., Fernández, E., Cerezo, R., ... Figueiredo, M. (2015). Transcultural analysis of the effectiveness of a program to promote self-regulated learning in Mozambique, Chile, Portugal, and Spain. Higher Education Research \& Development, 34(1), 173-187. doi: $\underline{10.1080 / 07294360.2014 .935932}$

Saadu, U. T., \& Adesokan, A. (2013). Personality types and coping strategies as correlates of students' academic achievement. Journal of Educational and Social Research, 3(5), 17-24. doi: 10.5901/jesr.2013.v3n5p17

Sagone, E., \& De Caroli, M. E. (2014). A correlational study on dispositional resilience, psychological well-being, and coping strategies in university students. American Journal of Educational Research, 2(7), 463-471. doi: 10.12691/education-2-7-5

Saklofske, D. H., Austin, E. J., Mastoras, S., M., Beaton, L., \& Osborne, S. E. (2012). Relationships of personality, affect, emotional intelligence and coping with student stress and academic success: Different patterns of association for stress and success. Learning and Individual Differences, 22(2), 251-257. doi:

$\underline{10.1016 / j . l i n d i f .2011 .02 .010}$

Salanova, M., Schaufeli, W. B., Martinez, I., \& Bresó, E. (2010). How obstacles and facilitators predict academic performance: The mediating role of study burnout and engagement. Anxiety, Stress and Coping, 23(1), 53-70. doi: $\underline{10.1080 / 10615800802609965}$

Schaufeli, W. B., Martínez, I. M., Pinto, A. M., Salanova, M., \& Bakker, A. B. (2002). Burnout and engagement in university students: A cross-national study. Journal of Cross-Cultural Psychology, 33(5), 464-481. doi: 10.1177/0022022102033005003

Schellenberg, B. J. I., \& Bailis, D. S. (2016). The two roads of passionate goal pursuit: Links with appraisal, coping, and academic achievement. Anxiety, Stress, \& Coping, 29(3), 287-304. doi: 10.1080/10615806.2015.1036047.

Serrano, C., \& Andreu, Y. (2016). Perceived emotional intelligence, subjective wellbeing, perceived stress, engagement and academic achievement of adolescents. Journal of Psychodidactics, 21(2), 357-374. doi: 10.1387/RevPsicodidact.14887 
Sobel, M. E. (1982). Asymptotic confidence intervals for indirect effects in structural equation models. Sociological Methods, 13, 290-312.

Spedding, J., Hawkes, A. J., \& Burgess, M. (2017). Peer assisted study sessions and student performance: The role of academic engagement, student identity, and statistics self-efficacy. Psychology, Learning \& Teaching, 16(1), 1-20. doi: $\underline{10.1177 / 1475725716687166}$

Struthers, C. W., Perry, R. P., \& Menec, V. H. (2000). An examination of the relationship among academic stress, coping, motivation, and performance in college. Research in Higher Education, 41(5), 581-592. doi: 10.1023/A:1007094931292

Tartas, M., Walkiewicz, M., Budziński, W., Majkowicz, M., Wójcikiewicz, K., \& Zdun-Ryżewska, A. (2016). The coping strategies during medical education predict style of success in medical career: A 10-year longitudinal study. BMC Medical Education, 16:186. doi: 10.1186/s12909-016-0706-1

Tobin, D. L., Holroyd, K. A., Reynolds, R. V. C., \& Wigal, J. K. (1989). The hierarchical factor structures of the Coping Strategies Inventory. Cognitive Therapy and Research, 13(4), 343-361. doi: 10.1007/BF01173478

Thomas, C. L., Cassady, J. C., \& Heller, M. L. (2017). The influence of emotional intelligence, cognitive test anxiety, and coping strategies on undergraduate academic performance. Learning and Individual Differences, 55, 40-48. doi: $\underline{10.1016 / j . l i n d i f .2017 .03 .001}$

Turner, M., Holdsworth, S., \& Scott-Young, C. M. (2017). Resilience at University: the development and testing of a new measure. Higher Education Research \& Development, 36(2), 386-400. doi: 10.1080/07294360.2016.1185398

Van der Colff, J. J., \& Rothmann, S. (2009). Occupational stress, sense of coherence, coping, burnout and work engagement of registered nurses in South Africa. South African Journal of Industrial Psychology, 35(1), 1-10. doi: 10.4102/sajip.v35i1.423 